\title{
Psychological Impact of the COVID-19 Pandemic on Palestinian Nursing Students: A Cross-Sectional Study
}

\author{
Abu-El-Noor NI* \\ Islamic University of Gaza, Associate Professor, Faculty of \\ Nursing, Palestine \\ *Correspondling author: Nasser Ibrahim Abu-El- \\ Noor, Islamic University of Gaza, Associate Professor, \\ Faculty of Nursing, Palestine
}

Received: March 20, 2021; Accepted: May 07, 2021; Published: May 14, 2021

\begin{abstract}
Introduction: The COVID-19 pandemic became a global pandemic in early 2020. The pandemic has many impacts on people's live posing a threat to their physical and mental health. Therefore, this study aimed to assess the psychological impact of COVID-19 pandemic on Palestinian nursing students residing in the Gaza Strip, Palestine.

Materials and Methods: A convenience sample of 345 nursing students from the Islamic University of Gaza completed on line questionnaire packet that included demographic data and the 7-item Generalized Anxiety Disorder Scale (GAD-7).

Results: Results from this study revealed that most of our participants were females (79.1\%), single (82.3\%), not working (90.4\%) and having no chronic disease $(94.8 \%)$. Variant levels of anxiety were reported by participants with $34.5 \%$ of them having mild, $31 \%$ moderate and $19.1 \%$ severe levels of anxiety. Levels of anxiety reported in this study were not impact by any study variables such as age, sex, study year, etc.

Conclusions and Implications for Practice: The results of this study revealed high levels of anxiety among nursing students. The closure of the universities, the new experience of e-learning along with the multi-stressors already prevailing in the Gaza Strip have contributed to this high level of anxiety. Universities and the health care system in the Gaza Strip should pay attention to reduce anxiety levels among students. This could be approached by providing online training courses or setting channels of one-to-one online or phone counseling for students to alleviate negative psychological effects and to enhance mental health of students.
\end{abstract}

Keywords: COVID-19; Nursing students; Psychological impact; GAD-7; Gaza Strip; Palestine; Anxiety

\section{Introduction}

On 30 January, the World Health Organization declared the 2019 coronavirus disease (COVID-19) outbreak a public health emergency of international concern [1]. On 12 February 2020, the novel coronavirus was named severe acute respiratory syndrome coronavirus 2 (SARS-CoV-2) while the disease associated with it is now referred to as COVID-19. It is a new strain of coronavirus that has not been previously identified in humans [2]. It is transmitted through large respiratory droplets and direct contact; other modes of transmission (i.e. airborne and faeco-oral) have also been proposed [3].

The estimated median incubation period is five to six days (range 0 to 14 days) [4]. It mostly attacks older people with compromised immune system. The median age of confirmed cases is around 59 years [5]. Initially, more than $80 \%$ of patients have asymptomatic or mild disease and recover, but about $15 \%$ may get severe disease including pneumonia, and around 5\% become critically ill with septic shock and/or multi-organ and respiratory failure [6]. Fatality rate is estimated to be around $2 \%$ among overall ages, but it ranges from $0.2 \%$ in people under 50 to $14.8 \%$ in those over 80 , and it is higher among patients with chronic comorbid conditions [7].
Up to March 5, 2020, Palestine was free of Corona virus (COVID-19). On 6 March, seven cases in Bethlehem City in the West Bank were found to be positive for COVID-19 [8]. The President of Palestine immediately declared an emergency state in Palestine including West Bank and the Gaza Strip. This resulted in closing clustering places including schools and universities. This is besides establishing several quarantining centers at entrance ports to quarantine people who are returning to Palestine from other countries. This policy limited the number of patients with COVID-19, especially in the Gaza Strip as up to August 23, all positive cases in Gaza were discovered among people in the quarantine centers.

Outbreaks of novel virus infections among people are always of public health concern, especially when there's little knowledge about the characteristics of the virus, how it spreads between people, how severe are the resulting infections and how to treat them [2]. This outbreak had several impacts on individuals' lives, including unbearable psychological pressure [9].

Several studies were conducted to detect psychological impact of COVID-19 on several groups of the populations such as general public health care providers $[10,11]$, general population $[9,12-14]$, elderly [15,16], children and adolescents [17] and university students 
[18-20].

The Gaza Strip is a small territory of $365 \mathrm{~km}^{2}$ with about two million inhabitants. It is located on the Eastern Mediterranean coast and belongs to the self-governing territories of Palestine. However, it is geographically completely separated from the other Palestinian territories of the West Bank. For over than 14 years, no free movement is possible in and out of the Gaza Strip and following the 2014 war, movement has been further restricted [21]. This situation poses different challenges to the region, such as high unemployment, especially among young people, dense population and stagnant economic and academic atmospheres [22].

Early on, the World Health Organization (WHO) advised implementation of and adherence to strict measures to reduce transmission of SARS-Co-2, including social distancing, staying at home to reduce transmission, stringent hand hygiene, sneezing and coughing etiquette, self-isolation in the presence of symptoms and testing for Coronavirus as well as consequent contact tracing of infected people with isolation and quarantine of suspected or active cases [23]. As a result, schools and universities were closed on early March 2020 and university students started a new challenge and a new experience of e-learning, which added to the multi-stressors prevailing among individuals living in the Gaza Strip, especially among university students with the new stress related to the new experience of e-learning and the worry about their future. Therefore, this study aimed to assess the psychological impact of COVID-19 pandemic on Palestinian nursing students residing in the Gaza Strip, Palestine.

\section{Methods and Materials}

\section{Design, population, setting and sampling}

A cross-sectional design was used in this study. The target population comprised of undergraduate nursing students enrolled in the second semester at the Faculty of Nursing at the Islamic University of Gaza. Data were collected after student had finished their final exams for the second semester. There were 1392 students enrolled in this semester, 920 of them are females and 412 males; 221 are enrolled in the midwifery department while the rest (1170) are in the nursing department. A convenience sample of 357 students completed an electronic version of the questionnaire. After excluding 12 cases, the remaining questionnaires became 345 .

\section{Instrument}

The instrument used in this study composed from two parts; the first part included demographic information about participants including age, gender, department, type of enrollment (regular student $v s$. upgrading student from associate degree to bachelor of science in nursing), working status, marital status, working condition, if having a chronic disease and number of family members. The other part of the instrument comprised of the 7-item Generalized Anxiety Disorder Scale (GAD-7). The GAD-7 was developed by Toussaint et al. [24] and it includes seven items based on seven core symptoms and inquires the frequency with which respondents suffered from these symptoms within the last two weeks. GAD-7 measures anxiety symptoms using a 4-point Likert scale ranging from zero to three, where $0=$ not at all, $1=$ several days, $2=$ over half the days and 3 $=$ almost every day, therefore, the total score will range from 0 to
21. The GAD-7 showed to be valid and reliable $[18,25]$ validated screening instrument, and it has demonstrated excellent internal consistency (Cronbach's $\alpha=0.884$ ) in this study.

\section{Data analysis}

The Statistical Package for Social Science (SPSS), version 18, was used to compute and analyze the data. Data was analyzed using descriptive statistics (mean, range, standard deviation, and percentage) and frequency distribution tables. ANOVA and $t$-test and test were used to examine statistical significance between differences of the means of different variables. Use correlations test was to examine if there were any correlation between different total score of GAD-7and sociodemographic variables. Prior to data analysis, 12 responses of the 357 questionnaires were excluded because there were three or more missing variables of the GAD-7. Missing variables were replaced by the mean of each item.

\section{Ethical considerations}

Prior to conducting this research study, approval from the Internal Review Board at the Islamic University of Gaza was obtained. Participants were informed about the purpose of the study at the opening statement and were assured that their participation is voluntary and that each one has the right to refuse to complete the questionnaire. Participants were assured that if they decided to refuse to be involved in the assessment process, this decision would not affect their grades. Data was collected anonymously from all participants. In the final report, confidentiality and anonymity will be maintained.

\section{Results}

Table 1 represent the socio-demographic characteristics of participants. The age of participants ranged between 18 and 45 years Table 1: Socio-demographic characteristics of participants.

\begin{tabular}{|c|c|c|c|}
\hline & & Frequency & $\%$ \\
\hline Age & \multicolumn{3}{|c|}{ Mean 21.33 ( \pm 2.98$) ;$ Range 18-45 year } \\
\hline \multirow{2}{*}{ Sex } & Male & 72 & 20.9 \\
\hline & Female & 273 & 79.1 \\
\hline \multirow{4}{*}{ Marital status } & Married & 59 & 17.1 \\
\hline & Single & 284 & 82.3 \\
\hline & divorced & 1 & 0.3 \\
\hline & widow & 1 & 0.3 \\
\hline \multirow{2}{*}{ Type of enrolment } & Regular students & 287 & 83.2 \\
\hline & Upgrading & 58 & 16.8 \\
\hline \multirow{2}{*}{ Department } & Nursing & 264 & 76.5 \\
\hline & Midwifery & 81 & 23.5 \\
\hline \multirow{4}{*}{ Level } & First Year & 54 & 15.7 \\
\hline & Second Year & 61 & 17.7 \\
\hline & Third Year & 127 & 36.8 \\
\hline & Fourth Year & 103 & 29.9 \\
\hline \multirow{2}{*}{ Working status } & Yes & 28 & 8.1 \\
\hline & No & 312 & 90.4 \\
\hline \multirow{2}{*}{ Having a chronic disease } & Yes & 11 & 3.2 \\
\hline & No & 327 & 94.8 \\
\hline Number of family members & \multicolumn{3}{|c|}{ Mean 7.07 ( \pm 3.23$)$; Range (1 to 25$)$} \\
\hline
\end{tabular}


Table 2: Frequency, percentage, mean and standard deviation of GAD-7 items.

\begin{tabular}{|c|c|c|c|c|c|c|}
\hline & Not at all sure & Several days & Over half the days & Nearly every day & \multirow{2}{*}{ Mean } & \multirow{2}{*}{ SD } \\
\hline & Freq. (\%) & Freq. (\%) & Freq. (\%) & Freq. (\%) & & \\
\hline Feeling nervous, anxious, or on edge & $34(9.9 \%)$ & $126(36.5 \%)$ & $102(29.6 \%)$ & $83(24.1 \%)$ & 1.68 & 0.95 \\
\hline Not being able to stop or control worrying & $80(\% 23.2)$ & $149(43.2 \%)$ & $62(18.0 \%)$ & $54(15.7 \%)$ & 1.26 & 0.99 \\
\hline Worrying too much about different things & $46(13.3 \%)$ & $131(38.0 \%)$ & $95(27.5 \%)$ & $73(21.2 \%)$ & 1.57 & 0.97 \\
\hline Trouble relaxing & $56(16.2 \%)$ & $138(40.0 \%)$ & $91(26.4 \%)$ & $60(17.4 \%)$ & 1.45 & 0.96 \\
\hline Being so restless that it's hard to sit still & $107(31.0 \%)$ & $150(43.5 \%)$ & $46(13.3 \%)$ & $42(12.2 \%)$ & 1.07 & 0.96 \\
\hline Becoming easily annoyed or irritable & $46(13.3 \%)$ & $130(37.7 \%)$ & $76(22.0 \%)$ & $93(27.0 \%)$ & 1.63 & 1.02 \\
\hline Feeling afraid as if something awful might happen & $84(24.3 \%)$ & $121(35.1 \%)$ & $77(22.3 \%)$ & $63(18.3 \%)$ & 1.34 & 1.04 \\
\hline
\end{tabular}

Table 3: Levels of anxiety among undergraduate nursing students.

\begin{tabular}{|c|c|c|c|c|c|c|c|c|c|c|}
\hline \multirow{2}{*}{ Level of anxiety } & \multicolumn{2}{|c|}{ All students } & \multicolumn{2}{|c|}{ First year } & \multicolumn{2}{|c|}{ Second year } & \multicolumn{2}{|c|}{ Third year } & \multicolumn{2}{|c|}{ Fourth year } \\
\hline & Freq. & $\%$ & Freq. & $\%$ & Freq. & $\%$ & Freq. & $\%$ & Freq. & $\%$ \\
\hline Normal & 53 & 15.4 & 9 & 16.7 & 10 & 16.4 & 14 & 11 & 20 & 19.4 \\
\hline Mild & 119 & 34.5 & 15 & 27.8 & 18 & 29.5 & 46 & 36.2 & 40 & 38.8 \\
\hline Moderate & 107 & 31 & 23 & 42.6 & 17 & 27.9 & 48 & 37.8 & 19 & 18.4 \\
\hline Severe & 66 & 19.1 & 7 & 13 & 16 & 26.2 & 19 & 15 & 24 & 23.3 \\
\hline
\end{tabular}

with the great majority of them $(82.03 \%)$ within the age group of 18-22 years. Most of our participants were females (79.1\%), single (82.3\%), not working (90.4\%) and having no chronic disease (94.8\%). The majority of our participants were enrolled as regular students (83.2\%) and came from the nursing department (76.5). About two thirds of participants were from third (36.8\%) and fourth (29.9\%) year students. Finally, the family size of participants ranged between one and 25 family members with a mean of 7.07.

\section{Analysis of GAD-7}

The results for frequency, percentage, mean and standard deviation of GAD-7 items are depicted in Table 2. The item "Feeling nervous, anxious, or on edge" had the highest mean (1.68) while "Being so restless that it's hard to sit still" had the lowest mean (1.07).

\section{Level of anxiety among nursing students}

Table 3 shows the different levels of anxiety among undergraduate nursing students. Participants reported varying degrees of anxiety with more than $60 \%$ of them reporting moderate to severe levels of generalized anxiety disorder. First year students had the highest percentage $(42.6 \%)$ of moderate anxiety while second year students have the highest percentage (26.2\%) of severe level of anxiety.

\section{Factors influencing level of anxiety}

Pearson correlation did not show a statistically significant correlation between level of anxiety and the variables age and number of family members. ANOVA and t test did detect any impact of study variables on the total score of GAD-7 (Table 4).

\section{Discussion}

This study aimed to assess psychological impact of COVID-19 on Palestinian undergraduate nursing students. Results from this study revealed variant levels of anxiety among participants (Table 3) with $31 \%$ of the participants having moderate level of anxiety and $19.1 \%$ having severe level. Such impact of COVID-9 is expected. A previous study revealed that public health emergencies, which applies
Table 4: Impact of study variable on total score of GAD-7.

\begin{tabular}{|c|c|c|c|}
\hline \multicolumn{2}{|c|}{ Variable } & \multirow{2}{*}{$\begin{array}{l}\text { Mean } \\
10.86\end{array}$} & \multirow{3}{*}{$\begin{array}{c}\text { P value } \\
0.155\end{array}$} \\
\hline \multirow{2}{*}{ Sex } & Male & & \\
\hline & Female & 9.76 & \\
\hline \multirow{2}{*}{ Marital status } & Married & 9.5 & \multirow{2}{*}{0.511} \\
\hline & Singe & 10.08 & \\
\hline \multirow{2}{*}{ Type of enrolment } & Regular students & 10.03 & \multirow{2}{*}{0.058} \\
\hline & Upgrading & 9.79 & \\
\hline \multirow{2}{*}{ Department } & Nursing & 10.0947 & \multirow{2}{*}{0.513} \\
\hline & Midwifery & 9.6543 & \\
\hline \multirow{4}{*}{ Level } & First Year & 9.41 & \multirow{4}{*}{0.692} \\
\hline & Second Year & 10.57 & \\
\hline & Third Year & 10.06 & \\
\hline & Fourth Year & 9.87 & \\
\hline \multirow{2}{*}{ Working status } & Yes & 8.89 & \multirow{2}{*}{0.316} \\
\hline & No & 10.11 & \\
\hline \multirow{2}{*}{ Having a chronic disease } & Yes & 8.82 & \multirow{2}{*}{0.491} \\
\hline & No & 10.09 & \\
\hline
\end{tabular}

to COVID-19, might lead to several psychological effects on college students such as anxiety, fear, and worry, among others [26]. Scores of GAD-7, reported by participants of this study, were not influenced by age, gender, and study year, type of enrolment, having a chronic disease or number of family members' variables.

Level of anxiety reported in this study is relatively high. It is higher than those reported in other related studies. A study conducted in China assessed psychological impact on university students [18] and revealed that about $25 \%$ of participants having varying degrees of anxiety $(21.3 \%$ with mild anxiety, $0.9 \%$ with moderate level of anxiety \& and $2.7 \%$ with high level of anxiety). Another study conducted in China revealed prevalence rates of anxiety and depression symptom 
of $7.7 \%$ and $12.2 \%$ among college students, respectively [20]. In Spain, moderate to extremely severe scores of anxiety (21.34\%), depression $(34.19 \%)$ and stress $(28.14 \%)$ were reported by Spanish university students [19].

The prevalence of high level of anxiety among Palestinian nursing students could be due to the fact that these students are studying nursing and go to practice at hospitals; especially that studies conducted to assess level of anxiety among health care providers reported high level of anxiety. For example, a study conducted in Singapore [27] found that $20.7 \%$ of health care providers had anxiety, $6.9 \%$ had stress, $10.3 \%$ had depression and $10.9 \%$ had post-traumatic stress disorder. In another study conducted in China, results revealed that $39.1 \%$ of the health care workers had psychological distress [11]. Therefore, nursing students might be afraid of contracting the disease during their practice; although, training in hospitals was suspended for about three months (March to June).

Other contributing factors that might contribute to high prevalence of anxiety among nursing students could be due to the exceptional conditions they live in the Gaza Strip. For example, Gaza suffers from siege imposed by Israel since 2006 with no free movement is possible in and out of the Gaza Strip. Following the 2014 war, movement of people and goods has been further restricted [21]. The new experience of e-learning is another factor that might contribute to the high level of anxiety among participants, especially that internet access is limited to many students and with the unstable availability of electricity (about 8-12 hours a day) will interrupt their study and affect their grades, which may affect their chance to get a job in the future. This is of especial concern especially that rates of poverty and unemployment in the Gaza Strip reached nearly $75 \%$ in 2019 [28]. These situations contributed to students' anxiety related to COVID-19 as this will affect their studies and therefore will affect their career and future employment $[14,18,29]$. Moreover, a study found that COVID-19 lockdown lead to worsening quality of sleep and insomnia symptoms among university students [30] which in turn may affect their academic performance and future career and increase their level of anxiety.

Other causes that might contribute to increasing levels of anxiety among university students were reported in the literature. For example, some studies argued that anxiety levels increase by social distancing practice and absence of interpersonal communication during the quarantine and lockdown due to the pandemic of COVID-19 [31,32]. Also, it has been argued that the increasing numbers of COVID-19 patients and suspected cases contributes to eliciting public worry about contracting the disease and increasing levels of anxiety [33]. Furthermore, with high rates of poverty and unemployment that prevails among individuals living in the Gaza Strip, they will be unable to purchase enough protective equipment such as masks, gloves and disinfectants. Shortage of protective devices and disinfectant may lead to increase feelings of unsafely and therefore may increase levels of anxiety.

Results from this study revealed that none of the study variables had an impact on levels of anxiety among participants. However, the author was expecting that fourth year students will report higher levels of anxiety, results showed that they had the lowest prevalence of moderate and severe (combined) levels of anxiety (41.7\%) compared to $50.1 \%$ (first year), $55.6 \%$ (second year) and $54.1 \%$ (third year) students. This expectation was based on literature, which argued that COVID-19 would have serious impact of career of students who will graduate in this year (fourth year students in this case). Sahu [34] argued that because these students are experiencing major interruptions in teaching and performance in the final part of their studies, they may likely graduate late due to the postponement of the final examination; which in turn may contribute to increasing levels of anxiety [35].

\section{Conclusions and Implications for Practice}

The results of this study revealed high level of anxiety among nursing students. The closure of the universities, the new experience of e-learning along with the multi-stressors already prevailing in the Gaza Strip have contributed to this high level of anxiety. Universities and the health care system in the Gaza Strip should pay attention to reduce anxiety levels among students. This could be approached by providing online training courses or setting channels of one-toone online or phone counseling for students to alleviate negative psychological effects and to enhance mental health of students [34].

\section{References}

1. World Health Organization. Responding to community spread of COVID-19. $2020 b$

2. European Centre for Disease Prevention and Control. COVID-19. 2020b.

3. European Centre for Disease Prevention and Control. Checklist for hospitals preparing for the reception and care of coronavirus 2019 (COVID-19) patients. 2020a.

4. World Health Organization. Coronavirus disease 2019 (COVID-19). 2020.

5. Li Q, Guan X, Wu P, Wang X, Zhou L, Tong Y, et al. Early transmission dynamics in Wuhan, China, of novel coronavirus-infected pneumonia. New England Journal of Medicine. 2020.

6. World Health Organization. WHO Director-General's remarks at the media briefing on COVID-2019 outbreak on 17 February 2020. 2020c.

7. Wu Z, McGoogan JM. Characteristics of and important lessons from the coronavirus disease 2019 (COVID-19) outbreak in China: summary of a report of 72314 cases from the Chinese Center for Disease Control and Prevention. Jama. 2020.

8. Ministry of Health. Daily report about Coronal Virus (COVID 19). 2020

9. Duan L, Zhu G. Psychological interventions for people affected by the COVID-19 epidemic. The Lancet Psychiatry. 2020; 7: 300-302.

10. Chen Q, Liang M, Li Y, Guo J, Fei D, Wang L, Li X. Mental health care for medical staff in China during the COVID-19 outbreak. The Lancet Psychiatry. 2020; 7: e15-e16.

11. Dai Y, Hu G, Xiong H, Qiu H, Yuan X. Psychological impact of the coronavirus disease 2019 (COVID-19) outbreak on healthcare workers in China. MedRxiv. 2020.

12. Rossi R, Socci V, Talevi D., Mensi S, Niolu C, Pacitti F, et al. COVID-19 pandemic and lockdown measures impact on mental health among the general population in Italy. Frontiers in Psychiatry. 2020; 11

13. Serafini G, Parmigiani B, Amerio A, Aguglia A, Sher L, et al. The psychological impact of COVID-19 on the mental health in the general population: Oxford University Press. 2020

14. Wang C, Horby PW, Hayden FG, Gao GF. A novel coronavirus outbreak of global health concern. The Lancet. 2020; 395: 470-473.

15. Meng $\mathrm{H}, \mathrm{Xu} \mathrm{Y}$, Dai J, Zhang $\mathrm{Y}$, Liu B, Yang $\mathrm{H}$. Analyze the psychological impact of COVID-19 among the elderly population in China and make corresponding suggestions. Psychiatry research. 2020; 289: 112983. 
16. Yang Y, Li W, Zhang Q, Zhang L, Cheung T, Xiang Y-T. Mental health services for older adults in China during the COVID-19 outbreak. The Lance Psychiatry. 2020; 7: e19.

17. Li S, Wang Y, Yang Y, Lei X, Yang Y. Analysis of influencing factors of anxiety and emotional disorders in children and adolescents during home isolation during the epidemic of novel coronavirus pneumonia. Chinese Journal of Child Health. 2020; 28: 1-9.

18. Cao W, Fang Z, Hou G, Han M, Xu X, Dong J, Zheng J. The psychological impact of the COVID-19 epidemic on college students in China. Psychiatry research. 2020: 112934

19. Odriozola-González P, Planchuelo-Gómez Á, Irurtia MJ, de Luis-García R. Psychological effects of the COVID-19 outbreak and lockdown among students and workers of a Spanish university. Psychiatry research. 2020; 113108

20. Wang Z, Yang H-L, Yang Y-Q, Liu D, Li Z-H, Zhang X-R, et al. Prevalence of anxiety and depression symptom, and the demands for psychological knowledge and interventions in college students during COVID-19 epidemic: A large cross-sectional study. Journal of affective disorders. 2020; 275: 188193.

21. UN Office for the Coordination of Humanitarian Affairs. Humanitarian Atlas 2019: United Nations. 2019

22. Albarqouni L, Elessi K, Abu-Rmeileh NM. A comparison between health research output and burden of disease in Arab countries: evidence from Palestine. Health Research Policy and Systems. 2018; 16: 25.

23. World Health Organization. Overview of Public Health and Social Measures in the context of COVID-19. 2020a.

24. Toussaint $A$, Hüsing $P$, Gumz A, Wingenfeld $K$, Härter $M$, Schramm $E$, et al Sensitivity to change and minimal clinically important difference of the 7-item Generalized Anxiety Disorder Questionnaire (GAD-7). Journal of affective disorders. 2020; 265: 395-401.

25. Spitzer RL, Kroenke K, Williams JB, Löwe B. A brief measure for assessing generalized anxiety disorder: the GAD-7. Archives of internal medicine. 2006 166: 1092-1097.
26. Mei S, Yu J, He B, Li J. Psychological investigation of university students in a university in Jilin Province. Medicine and Society. 2011; 24: 84-86.

27. Tan BY, Chew NW, Lee GK, Jing M, Goh Y, Yeo LL, et al. Psychological impact of the COVID-19 pandemic on health care workers in Singapore. Annals of Internal Medicine. 2020

28. Middle East Monitor. Gaza: Poverty and unemployment rates at 75\%. 2019.

29. Cornine A. Reducing nursing student anxiety in the clinical setting: An integrative review. Nursing education perspectives. 2020; 41: 229-234.

30. Marelli S, Castelnuovo A, Somma A, Castronovo V, Mombelli S, Bottoni D, et al. Impact of COVID-19 lockdown on sleep quality in university students and administration staff. Journal of Neurology. 2020.

31. Kmietowicz Z. Rules on isolation rooms for suspected covid-19 cases in GP surgeries to be relaxed: British Medical Journal Publishing Group. 2020.

32. Xiao C. A novel approach of consultation on 2019 novel coronavirus (COVID19)-related psychological and mental problems: structured letter therapy. Psychiatry investigation. 2020; 17: 175.

33. Bao Y, Sun Y, Meng S, Shi J, Lu L. 2019-nCoV epidemic: address mental health care to empower society. The Lancet. 2020; 395: e37-e38.

34. Sahu P. Closure of universities due to Coronavirus Disease 2019 (COVID-19): impact on education and mental health of students and academic staff. Cureus. 2020; 12.

35. Wang C, Pan R, Wan X, Tan Y, Xu L, Ho C S, et al. Immediate psychological responses and associated factors during the initial stage of the 2019 coronavirus disease (COVID-19) epidemic among the general population in China. International journal of environmental research and public health. 2020; 17: 1729 . 